\title{
Development and validation of the Morphing Fear Questionnaire (MFQ)
}

Article

Accepted Version

Zysk, E., Shafran, R., Williams, T. I. and Melli, G. (2016)

Development and validation of the Morphing Fear

Questionnaire (MFQ). Clinical Psychology \& Psychotherapy, 23 (6). pp. 533-542. ISSN 1063-3995 doi:

https://doi.org/10.1002/cpp.1987 Available at https://centaur.reading.ac.uk/43513/

It is advisable to refer to the publisher's version if you intend to cite from the work. See Guidance on citing.

To link to this article DOI: http://dx.doi.org/10.1002/cpp.1987

Publisher: Wiley

All outputs in CentAUR are protected by Intellectual Property Rights law, including copyright law. Copyright and IPR is retained by the creators or other copyright holders. Terms and conditions for use of this material are defined in the End User Agreement.

\section{www.reading.ac.uk/centaur}

\section{CentAUR}

Central Archive at the University of Reading 
Reading's research outputs online 


\section{Development and validation of the Morphing Fear Questionnaire (MFQ)}

\begin{tabular}{|r|l|}
\hline Journal: & Clinical Psychology \& Psychotherapy \\
\hline Manuscript ID & CPP-1139.R1 \\
\hline Wiley - Manuscript type: & Research Article \\
\hline Date Submitted by the Author: & 27-Sep-2015 \\
\hline Complete List of Authors: & $\begin{array}{l}\text { Zysk, Eva; Nottingham Trent University, Division of Psychology } \\
\text { Shafran, Roz; University Collage London, Institute of Child Health } \\
\text { Williams, Tim; University of Reading, Institute of Education } \\
\text { Melli, Gabriele; Institute of Behavioral and Cognitive Psychology and } \\
\text { Psychotherapy of Florence, }\end{array}$ \\
\hline Keywords: & $\begin{array}{l}\text { morphing fear, transformation obsessions, mental contamination, } \\
\text { obsessive compulsive disorder, assessment, psychometric scale }\end{array}$ \\
\hline
\end{tabular}




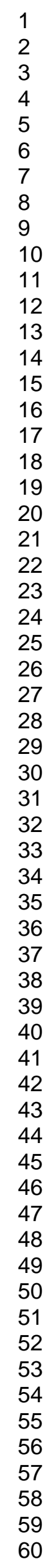

Development and validation of the Morphing Fear Questionnaire (MFQ) 


\section{Abstract}

Morphing fears (also called transformation obsessions) involve concerns that a person may become contaminated by and acquire undesirable characteristics of others. These symptoms are found in patients with OCD and are thought to be related to mental contamination. Given the high levels of distress and interference morphing fears can cause, a reliable and valid assessment measure is needed. This article describes the development and evaluation of the Morphing Fear Questionnaire (MFQ), a 13-item measure designed to assess for the presence and severity of morphing fears. A sample of 900 participants took part in the research. Of these, 140 reported having a current diagnosis of OCD (SR-OCD) and 760 reported never having had OCD (N-OCD; of whom 24 reported a diagnosis of an anxiety disorder and 23 reported a diagnosis of depression). Factor structure, reliability, and construct and criterionrelated validity were investigated. Exploratory and confirmatory factor analyses supported a one-factor structure replicable across the N-OCD and SR-OCD group. The MFQ was found to have high internal consistency and good temporal stability, and showed significantly greater associations with convergent measures (assessing obsessive-compulsive symptoms, mental contamination, thought-action fusion and magical thinking) than with divergent measures (assessing depression and anxiety). Moreover, the MFQ successfully discriminated between the SR-OCD sample and the N-OCD group, anxiety disorder sample, and depression sample. These findings suggest that the MFQ has sound psychometric properties and that it can be used to assess morphing fear. Clinical implications are discussed. 
Key Practitioner Message:

- Little remains known about morphing fears, but it is an important area of investigation due to symptoms being highly distressing and often debilitating

- Because morphing fears commonly present as obscure symptoms, they may not be recognised as a type of OCD

- The MFQ is a robust measure with clinical utility; it can facilitate recognition and assessment of morphing fears

- The MFQ will allow for further investigations of the prevalence, correlates and treatment outcomes of morphing fears.

Key words: morphing fear, transformation obsessions, mental contamination, obsessive-compulsive disorder, assessment, psychometric scale 
Contamination concerns and washing compulsions are the most common features of obsessive-compulsive disorder (OCD), occurring in $27-55 \%$ of people with the disorder (Calamari et al., 2004; Foa \& Kozak, 1995; Rachman, 2004; Rachman \& Hodgson, 1980; Rasmussen \& Eisen, 1992). In addition to the familiar construct of contamination fears elicited by physical contact with a contaminant, it has been suggested there exists “mental contamination” (Rachman, 1994, 2004, 2006). Mental contamination refers to feelings of internal or psychological dirtiness and urges to wash which arise in the absence of direct contact with a noxious substance, or following contact with something others would not deem contaminating. Mental contamination has been suggested to take a variety of forms, including a fear of “morphing". Morphing fears involve a fear of change of one's personal self through being tainted by or acquiring undesirable mental, physical or social characteristics of others (Rachman, 2006). Morphing fears have also been referred to as "transformation obsessions" (Volz \& Heyman, 2007) and “emotional contamination” (Hevia, 2009).

Morphing fears can be evoked with or without physical contact and can lead to avoidance of touching, being in the vicinity of, looking at, hearing, or thinking about "undesirable" people due to fear of becoming contaminated by them and acquiring their unwanted traits (Rachman, 2006). In extreme instances, patients are afraid of transforming into this undesirable person or, in the case of children, also an animal or thing (Volz \& Heyman, 2007). Patients may avoid a specific person or a particular group of people considered inferior or undesirable by the sufferer or society. These feared individuals have included those of low status; certain ethnic groups; people with mental illnesses, addictions, physical defects or other undesirable attributes (e.g. obesity); those considered incompetent, unpopular, or eccentric; and those who are unfortunate (e.g. unlucky, homeless), immoral or "bad" (Coughtrey, Shafran, Lee, \& 
Rachman, 2013; Hevia, 2009; Rachman, 2006; S. Rachman, personal communication, 19 October, 2009; Volz \& Heyman, 2007). These distressing symptoms can cause avoidance (e.g. of the feared person's airstream, of uttering words containing the first letter of the person's name), neutralising (e.g. touching "purifying” objects), discarding possessions, overt washing behaviours, mental cleansing, and thought suppression, in addition to checking and reassurance seeking behaviours to ensure the sufferer is not becoming like someone else (Hevia, 2009; Rachman, 2006; Volz \& Heyman, 2007).

One specific clinical example is presented in Zysk, Shafran and Williams (2015) in which "James", a young adult man with an unstable sense of self held beliefs he was vulnerable to his intelligence, morals and emotional state being eroded or changed (e.g. becoming superstitious, sexist and insecure) and to being changed in his appearance (e.g. becoming less attractive). Additionally, the patient feared others could pick up his own qualities, for instance that he would infect others with his low mood. James believed such changes could occur through physical contact, proximity or an infected atmosphere. He engaged in avoidance behaviour and compulsions that were geared at stopping him from changing, such as hand-washing and repetition of facts.

Due to the fact that morphing fears commonly present as obscure symptoms, they may not be recognised as a type of OCD. It is reported that morphing fear is sometimes misdiagnosed as psychosis (Volz \& Heyman, 2007); however, it is proposed to be a subtype of OCD because: sufferers are not delusional and can acknowledge their fear is irrational at some point of their psychopathology (e.g. when the threat is not imminent); thoughts about transformation are recurrent, intrusive and unpleasant, causing anxiety and distress; attempts are made to resist the fearful 
thoughts; sufferers perform repetitive behaviours to prevent the feared change; morphing fear co-occurs with or involves a history of contamination fears and OCD; and contact with a feared person can lead to feelings of contamination and urges to wash or neutralise (cf. American Psychiatric Association [APA], 2013; Rachman, 2006). Patients commonly interpret this threat as fear of becoming contaminated and fundamentally changed by others, bearing close resemblance to mental contamination.

Two types of cognitive errors may be related to morphing fear: thought-action fusion (TAF) and magical thinking. TAF is a cognitive bias commonly observed in people with OCD (Emmelkamp \& Aardema, 1999; Gwilliam, Wells, \& CartwrightHatton, 2004; Rachman, Thordarson, Shafran, \& Woody, 1995; Shafran, Thordarson, \& Rachman, 1996) and anxiety disorders (Abramowitz, Whiteside, Lynam, \& Kalsy, 2003; Rassin, Diepstraten, Merckelbach, \& Muris, 2001; Rassin, Merckelbach, Muris, $\&$ Schmidt, 2001). TAF involves two components: the belief that having negative thoughts and impulses is morally akin to carrying out these acts (moral type), and that thinking about a negative event makes it more likely to occur (likelihood type) (Shafran et al., 1996). Pertinently, TAF has been shown to be highly associated with mental contamination (Radomsky, Rachman, Shafran, Coughtrey, \& Barber, 2014). Magical thinking involves unscientific beliefs about causation held by an individual that are not culturally endorsed (Chapman, Chapman, \& Miller, 1982; Eckblad \& Chapman, 1983). Unlike with TAF, magical ideation is a broader concept that does not solely pertain to the belief that one's thoughts have the power to influence events (Berle \& Starcevic, 2005). While magical thinking is most often attributed as an indicator of schizotypy (Bolton, Dearsley, Madronal-Luque, \& Baron-Cohen; 2002; Chapman, Chapman, Kwapil, Eckblad, \& Zinser, 1994; Eckblad \& Chapman, 1983), Einstein and Menzies (2004a, 2004b, 2006) suggest that magical thinking is also a 
common feature of OCD, and patients with OCD report more magical ideation than patients with anxiety disorders. Fear of morphing is similar to magical thinking because it is based on impossible events (unscientifically-grounded transference of qualities).

Little remains known about the manifestation, phenomenology, correlates and prevalence of adult morphing fears, and symptoms are not widely recognised by mental health practitioners. The availability of a robust measure of morphing fears would be useful for further research into this understudied phenomenon and in clinical practice. The aim of the current study was thusly to develop and validate such a measure (called the Morphing Fear Questionnaire; MFQ) to assess for fears, thoughts, and behaviours related to morphing. Based on theory and previous research it was hypothesised that i) people reporting a diagnosis of OCD will score higher on the MFQ than the control non-OCD population, those with a self-reported anxiety disorder, and those with self-reported depression; and ii) the MFQ will correlate more strongly with symptoms of OCD, mental contamination, thought-action fusion, and magical thinking than with symptoms of anxiety and depression.

\section{Method}

\section{Ethics}

The study received ethical approval from the University of Reading (2010/60/RS; 2009/156/RS) and the Berkshire NHS Research Ethics Committee (07/Q1602/71; 10/H0505/61).

\section{Preliminary questionnaire development}

A preliminary morphing fear questionnaire was designed and tested in a pilot study using data from 328 participants (mean age $=28.52$ years, $S D=8.17,63 \%$ female; cf. Zysk, 2013). This helped shape the development of the second version of 
the measure which is reported in the current paper. The preliminary measure was composed following research into theoretical views of morphing fears; reviewing all available known literature, case studies, posts by sufferers on online forums; listening to past interviews conducted with morphing-fearful patients; and speaking with therapists who have previously encountered patients with these symptoms. The preliminary measure was designed following recommendations for scale development (e.g. Furr, 2011; Rust \& Golombok, 2009) and comprised of a 36-item pool which assessed for morphing-related concerns. Positive items (acquisition of positive characteristics) were included in order to assess their relevance to morphing obsessions.

Participants' written responses indicated that 17 items were being consistently misinterpreted and were therefore removed. The 19-item preliminary measure had acceptable internal reliability (Cronbach's $\alpha=0.75$ ) and showed initial evidence of criterion-related validity in its ability to discriminate between $\mathrm{OC}$ and non-OC groups, and convergent validity in its significant strong positive relationship with the Obsessional Compulsive Inventory Short Version ( $r=.50$; Foa et al., 2002) and the Vancouver Obsessional Compulsive Inventory for Mental Contamination ( $r=.57$; Rachman, 2006). In addition, it showed a significant moderate positive association with both the Thought-Action Fusion Scale $(r=.39$; Shafran, Thordarson, \& Rachman, 1996) and the Magical Ideation Scale ( $r=.43$; Eckblad \& Chapman, 1983).

\section{Item reduction}

The final MFQ was based on items of the preliminary measure, some of which were altered to ensure clarity, specificity, non-redundancy, and relevance. In particular, pairs of items that had similar wording and were highly correlated $(r>.45$; Abramowitz, Huppert, Cohen, Tolin, \& Cahill, 2002; Rapee, Craske, Brown, \& 
Barlow, 1996) were considered redundant, and items with the lower corrected itemtotal correlation were removed. Positive items showed low corrected item-total correlation and, as theory suggests morphing symptoms should be conceptualised as a type of OCD which is characterised by unwanted and distressing thoughts, it was thought that negative morphing fears would be of more relevance in clinical assessment and only these were retained. An item was added to assess fear of losing parts of oneself (referred to as "reverse morphing").

The final MFQ comprises 13 items. No reverse-scored items are used. Statement choices are scored from 0 (not at all) to 4 (very much); the range of scores therefore lies between 0 and 52. Respondents are asked to provide a short explanation or specific example for any two questions with which they agree much or very much. The measure takes 2-4 minutes to complete.

\section{Participants}

A control sample was recruited from the general population through informational posters, flyers, and emails around the university and community. Emailed individuals and contacts of the primary investigator were asked to pass along the study information to others with an aim of snowball sampling. Psychology undergraduates recruited through an online research panel completed the study for course credit $(n=105)$. A sample of people with a self-reported current diagnosis of OCD was collected through distributing study information at national OCD charity events and to OCD support groups, and through placing advertisements on support group websites. Information was also given to mental health practitioners and distributed at a conference for mental health professionals to be circulated to OCD patients. 
The participant pool was made up of 900 adults with a mean age of $30.02(S D=$ 10.29, range: $18-73,64.8 \%$ female). Participants were mainly from the UK $(80.8 \%)$, but the sample included respondents from other parts of Europe $(n=31)$, North America $(n=119$; of these, 92 were from Canada), Oceania $(n=7)$, Africa $(n=7)$, Asia $(n=5)$, and the Middle East $(n=3)$. Of the 873 who answered the ethnicity question, the large majority identified themselves as white $(n=767,78.8 \%), 52$ as Asian, 12 black, 29 mixed race, and 13 other ethnicity. Over half of the sample (53.7\%) was not religious, $43.2 \%$ identified with a religion (of these, $78.7 \%$ were Christian), and the remainder (3.1\%) did not respond to this question.

Seven hundred and sixty (84.4\%) respondents reported never having had OCD $(\mathrm{N}-\mathrm{OCD}$ : mean age $=29.35, S D=9.89$, range: $18-67,64.1 \%$ female $)$. The majority of this sample $(85.3 \%)$ scored below the cut-score $($ i.e. $\leq 21)$ on the Obsessive Compulsive Inventory - Short Version (OCI-R, Foa et al., 2002), indicating a sample unlikely to suffer from OCD. Of the N-OCD group, 24 self-reported having a current diagnosis of an anxiety disorder (SR-A; mean age $=28.25, S D=7.48$, range: $18-52$, $75.0 \%$ female), and 23 self-reported having a current diagnosis of major depression (SR-D; mean age $=28.43, S D=9.27$, range: $19-52,60.9 \%$ female). The SR-A group had a significantly higher mean score on the Beck Anxiety Inventory (Beck \& Steer, $1990 ; M=16.36, S D=12.09)$ than did those not reporting an anxiety disorder $(M=$ $7.95, S D=8.24, t(13.58)=-2.57, p=.023, r=.57)$, and the SR-D group had a significantly higher mean score on the Beck Depression Inventory-II (Beck, Steer \& Brown, 1996; $M=22.71, S D=20.50)$ than did those not reporting depression $(M=$ 9.94, $S D=9.11, t(307)=-3.53, p<.001, r=.20)$ in those who completed these measures. 
One hundred and forty participants (15.6\%) self-reported having a current diagnosis of OCD (SR-OCD; mean age $=33.62, S D=11.63$, range: $18-73,68.6 \%$ female). The majority ( $84.3 \%$ ) scored above the cut-score (i.e. $>21)$ on the OCI-R, indicating a sample likely to suffer with OCD.

\section{Measures}

Morphing Fear Questionnaire (MFQ). As described above.

Vancouver Obsessional Compulsive Inventory - Mental Contamination Scale (VOCIMC; Rachman, 2006). This measure consists of 20 items assessing the presence of mental contamination. Items are rated on a 5-point Likert scale from 0 (not at all) to 4 (very much). Radomsky et al. (2014) have shown the VOCI-MC has excellent internal consistency (Cronbach's $\alpha=.93-.97$ ), good discriminant validity between those with contamination OCD and other groups, good convergent validity with the contamination subscale of the VOCI (cf. Thordarson et al., 2004), and good divergent validity with symptoms of depression on the BDI-II (Beck, Steer, \& Brown, 1996). It has shown a one-factor structure both in clinical and non-clinical samples, and adequate temporal stability (Melli, Carraresi, Stopani, Radomsky \& Bulli, 2015). In the present study internal consistency was excellent for both the N-OCD and SR-OCD subgroups $(.94 \leq \alpha \geq .96)$.

Obsessional Compulsive Inventory - Short Version (OCI-R; Foa et al., 2002). The OCI-R assesses OCD symptomatology and severity using 18 items from 6 subscales that are rated on a 5-point Likert scale from 0 (not at all distressed/bothered) to 4 (extremely distressed/bothered). The measure is reported to have good to excellent internal consistency, temporal stability, and convergent validity (e.g. washing subscale: Cronbach's $\alpha=.86 ; r_{s}=.86$; strong correlation with Rachman and Hodgson's 1980 Maudsley Obsessive-Compulsive Inventory washing subscale, $r_{s}=$ 
.78 , respectively). For the present study, the internal consistency for the OCI-R was very good in both the N-OCD and SR-OCD samples (Cronbach's $\alpha=.89$ and .86 , respectively).

Thought-Action Fusion Scale (TAF Scale; Shafran et al., 1996). This 19-item scale is used to assess aspects of TAF. Participants rate how much they agree or disagree with statements on a 5-point Likert scale ranging from 0 (disagree strongly) to 4 (agree strongly). The scale has shown very good internal consistency (Cronbach's $\alpha=$ .85-.96; Rassin, Merckelbach, et al., 2001; Shafran et al., 1996), but poor temporal stability $(r=.52$; Rassin, Merckelbach, et al., 2001). TAF scores have been found to positively correlate with measures of OC symptoms, and the scale is able to discriminate between clinical and non-clinical samples (Rassin, Merckelbach, et al., 2001; Shafran et al., 1996). In the present study internal consistency was excellent in both the N-OCD and SR-OCD groups (Cronbach's $\alpha=.93$ and .95, respectively). Magical Ideation Scale (MIS; Eckblad \& Chapman, 1983). This 30-item true-false scale is the most widely used instrument to assess magical thinking (Kingdon, Egan, \& Rees, 2012). Seven items are reverse coded. The MIS has demonstrated good internal consistency (Cronbach's $\alpha=.78-.92)$ and test-retest reliability $(r=.80-.82$; Chapman et al., 1982). In the present study internal consistency was also very good in both samples $(.80 \leq \alpha \geq .86)$.

Beck Anxiety Inventory (BAI; Beck \& Steer, 1990). The BAI lists 21 cognitive, somatic and behavioural symptoms of anxiety. Participants rate their symptom severity for each of these items using a 4-point scale ranging from 0 (not at all) to 3 (severely, I could barely stand it). The BAI has shown excellent internal consistency (Cronbach's $\alpha=.94)$ and acceptable test-retest reliability $(r=.67$; Fydrich, Dowdall, 
\& Chambless, 1992), and is widely used in a variety of clinical and research contexts. In the present study internal consistency was also excellent in both samples ( $\alpha$ s $=.92)$. Beck Depression Inventory-II (BDI-II; Beck et al., 1996). The 21-item self-report questionnaire assesses the presence and severity of the affective, cognitive, motivational, psychomotor, and vegetative components of depression. Items are scored from 0 (absent) to 3 (severe). It has shown excellent internal consistency (Cronbach's $\alpha=.91)$ and test-retest reliability $(r=.93)$, and is one of the most widely used measures for assessing depression in research and clinical practise. In the present study internal consistency was also excellent in both samples $(.93 \leq \alpha \geq .94)$.

\section{Procedure}

The questionnaires were made available online using a secure web-based survey programme, and in paper format for those who requested it $(n=11)$. The MFQ was always presented first, and the other scales used for testing relationships with other constructs were administered in counterbalanced fashion to control for order and sequence effects. The questionnaires took approximately 45 minutes to complete, and support options and a written debrief of the research aims were provided upon completion. Participants could remain anonymous in the study. Participants who left their contact details were invited by email to complete the MFQ again at a later date to test temporal stability of scores. Eighty-four participants (25 SR-OCD) completed the MFQ a second time approximately after an 18 month interval.

\section{Results}

\section{Gender and Religiousness Differences}

There were no significant differences in total scores on the MFQ between men $(M=1.70, S D=2.74)$ and women $(M=1.84, S D=3.57)$ reporting never having had OCD, $t(758)=-.55, p=.584, r=.02 ;$ and men $(M=9.39, S D=10.89)$ and women $(M$ 
$=6.76, S D=8.31)$ self-reporting current $\mathrm{OCD}, t(138)=1.57, p=.119, r=.13$. There was a significant difference in total MFQ scores between those who are religious $(M=$ $2.15, S D=3.67)$ and those who are not $(M=1.50, S D=2.91)$ who reported never having had OCD, $t(584.96)=-2.62, p=.009, r=.11$. In the self-reported current OCD group the difference between those who are religious $(M=7.94, S D=9.92)$ and those who are not $(M=6.38, S D=8.03)$ was not significant, $t(125)=-.95, p=.342, r$ $=.08$.

\section{Factor structure analyses}

The factor structure of the MFQ was initially investigated through a crossvalidation procedure on the $\mathrm{N}-\mathrm{OCD}$ data. This sample was randomly divided into two sub-groups using the SPSS 18.0 "random sample of cases" function with the subgroup size set at "approximately 50\%”. An exploratory (common) factor analysis (EFA) was carried out using data from one sub-group $(n=379)$; a set of measurement models was then specified and a confirmatory factor analysis (CFA) was performed using data from the second sub-group $(n=381)$.

Since a substantial number of items in both subgroups showed values of skewness and kurtosis that fell outside the $[-1 ;+1]$ range recommended by Muthén and Kaplan (1985) for using maximum likelihood estimator (see Table 1), factor analyses were performed in Mplus 6.1 using the mean and variance adjusted weighted least squares estimator (WLSMV, Muthén, du Toit, \& Spisic, 1997). When using WLSMV estimator, Mplus 6.1 provides fit indices for EFA analogous to those of CFA, i.e., the Tucker-Lewis Index (TLI) the Comparative Fit Index (CFI) and the Root Mean Square Error of Approximation (RMSEA). Following Marsh, Hau, and Wen (2004), values $\geq .90$ were considered as acceptable and $\geq .95$ as optimal for the 
TLI and the CFI, and values $\leq .08$ as acceptable and $\leq .06$ as optimal for the RMSEA. The use of multiple indices provides a conservative and reliable evaluation of model fit relative to the use of a single-fit index. A change in CFI of less than .01 (Chen, 2007; Cheung \& Rensvold, 2001) or a change in RMSEA of less than .015 (Chen, 2007) would provide evidence for a more parsimonious model, and this was considered in the analyses.

\section{Exploratory factor analyses}

The Keyser-Meyer-Olkin (KMO) measure of the sampling adequacy was .89, indicating that the correlation matrix was suitable for factor analysis (Kaiser, 1974). Bartlett's test of sphericity (Bartlett, 1954) was significant, which also suggested that factor analysis was suitable.

The issue of determining the number of factors to extract was determined by performing dimensionality analyses on the polychoric correlation matrix of MFQ items through Minimum Average Partial correlation statistic (MAP; Velicer, 1976) and parallel analysis (PA) with optimal implementation (Timmerman \& LorenzoSeva, 2011). On the basis of the recommendations of Buja and Eyuboglu (1992), PA was performed on 1000 random correlation matrices obtained through permutation of the raw data and following Longman, Cota, Holden, and Fekken (1989) both the mean eigenvalues and the 95 th percentile eigenvalues were considered. These analyses were performed with FACTOR8 (Lorenzo-Seva \& Ferrando, 2006). PA suggested the extraction of only one factor both when mean percentile was considered and when 95th percentile was considered. MAP reached its lowest value at one factor (.032, $.043, .113, .351, .999)$. Taken together, these results suggested the one factor solution was most appropriate. 
EFA was performed on the first sub-group $(n=379)$ with the number of factors to extract set to 1 . Following the criteria stated above, the one-factor solution showed excellent fit indices $(\mathrm{CFI}=.97, \mathrm{TLI}=.96, \mathrm{RMSEA}=.05)$ and all the items substantially (i.e., $\geq .63$ ) loaded on the first factor, as shown in Table 1.

\section{[INSERT TABLE 1 ABOUT HERE]}

\section{Confirmatory factor analyses}

CFA was then used on the second sub-group of the N-OCD sample $(n=381)$. Consistently with the EFA results, the one-factor model showed an excellent fit (CFI = .97 TLI $=.97$, RMSEA $=.04)$. The same measurement model for the MFQ was tested on the SR-OCD group $(n=140)$. In this clinical sample, the fit indices for the onefactor model indicated once again an excellent fit $(\mathrm{CFI}=.98, \mathrm{TLI}=.98, \mathrm{RMSEA}=$ .06). In summary, the results of the CFAs showed that the one-factor solution met all the criteria for an optimal fit.

\section{Item analysis and reliability}

Table 1 also displays the results of item analyses in both groups. The minimum requirement for internal consistency (Kline, 1993) was met; high Cronbach's alphas indicated good reliability in the N-OCD $(\alpha=.81)$ and excellent reliability in the SR-OCD $(\alpha=.90)$ groups. Corrected item-total correlations were never smaller than .40 in either group, and mean inter-item correlations were .30 in the N-OCD group and .39 in the SR-OCD group which are considered adequate values for narrow constructs (Clark \& Watson, 1995). In no case was the alpha-if-item-deleted higher than the computed alpha, suggesting that all items contribute to the internal consistency of the scales. 
As previously stated, eighty-four participants completed the retest after an 18 month interval. At the first administration, the mean MFQ score for this sample was $4.25(S D=6.32$, range: $0-26)$. At the retest, the mean score was $3.88(S D=6.97$, range: $0-41)$. Test-retest reliability was good $(r=.73, p<.001)$, particularly considering the long time frame. The mean scores of the first and second administration were compared with paired-samples t-test and there was no significant difference found, indicating good temporal stability of the scale.

\section{Construct validity}

It was predicted that the MFQ score would be more strongly correlated with the OCI-R, VOCI-MC, TAF and MIS (convergent measures), than with the BDI-II and BAI (divergent measures). As shown in Table 2, convergent correlations ranged from .46 to .52 in the N-OCD group, and from .45 to .66 in the SR-OCD group, whereas discriminant correlations ranged from .27 to .32 in the N-OCD group, and from .27 to .34 in the SR-OCD group. As expected, MFQ scores in both samples were significantly more strongly correlated with symptoms of OCD, mental contamination, thought-action fusion and magical thinking, than with depression and anxiety; $z$ contrast tests (Westen \& Rosenthal, 2003) showed significant differences between convergent and divergent measures both in N-OCD $(z=8.43, p<.001)$ and SR-OCD $(z=4.14, p<.001)$ groups. These results indicate that the scale has excellent construct validity.

\section{[INSERT TABLE 2 ABOUT HERE]}

\section{Criterion-related validity}

An independent samples $t$-test showed the SR-OCD group had a significantly higher mean score $(M=7.59, S D=9.24)$ on the MFQ than the N-OCD group $(M=$ $1.79, S D=1.79), t(145.58)=-7.34, p<.001$, and this was a large effect $(r=.52)$. A 
one-way ANOVA was performed comparing mean MFQ scores of the SR-OCD group with those from the N-OCD group reporting an anxiety disorder in the absence of depression $(M=2.71, S D=3.52)$, and those reporting depression in the absence of anxiety $(M=1.30, S D=3.96)$. A significant main effect of group was found, $F(2,184)$ $=8.19, p<.001, r=.29$. Games-Howell post-hoc comparisons indicated that the SROCD group scored significantly higher than both the SR-A and the SR-D groups (both $p \mathrm{~s}<.001)$. In combination, the ability of the MFQ to discriminate between the SR-OCD and other groups provides evidence towards its criterion-related validity.

\section{Discussion}

The Morphing Fear Questionnaire was developed to enable assessment of morphing fears, as previously no such measure existed. The results reported here suggest that the MFQ is a unidimensional, reliable and valid assessment of morphing fears. The MFQ has shown high internal consistency and good temporal stability, evidencing reliability over a long time period. The MFQ can successfully discriminate between those reporting a current diagnosis of OCD and those reporting never having had such a diagnosis, lending support towards criterion-related validity. Significant differences between scores on the MFQ of the sub-samples reporting OCD, anxiety, and depression provided evidence that morphing fears are more relevant to OCD than to anxiety and depressive disorders. Furthermore, high MFQ scores were found to be more closely associated with high scores on the OCI-R and VOCI-MC measures, than with the BAI and BDI-II. The co-occurrence of morphing fears, obsessive-compulsive symptoms, and mental contamination suggest that these symptoms may be related.

Morphing fears were also found to be associated with magical thinking and thought-action fusion. This finding offers some support for the hypothesis that fear of morphing is linked with cognitive biases and magical ideation that are characteristic of 
OCD. While magical thinking is commonly attributed as an indicator of schizotypy and in this study morphing fears were correlated with magical thinking, it should be noted that this does not necessarily mean that morphing fears are linked with psychosis. Other authors have hypothesised that these traits are distinct constructs (cf. Rachman, 2006; Volz \& Heyman, 2007). When not under current threat, sufferers do not believe morphing is physically possible and thereby these fears are distinct from delusions.

Previous research using non-clinical samples has shown positive associations between religiosity and thought-action fusion (Abramowitz, Deacon, Woods, \& Tolin, 2004; Berman, Abramowitz, Pardue \& Wheaton, 2010; Rassin \& Koster, 2003; Sica, Norvara, \& Sanavio, 2002; Siev \& Cohen, 2007) and large group differences in levels of magical thinking between those who identify with religion and those who do not (Caldwell-Harris, Wilson, LoTempio \& Beit-Hallahmi, 2011). Given the current findings that morphing fears are associated with thought-action fusion and magical thinking, it is not surprising higher levels of morphing fears were found in the religious group of those without $\mathrm{OCD}$. These cognitive biases have been particularly evident in Christians (Rassin \& Koster, 2003; Siev \& Cohen, 2007) which made up a large proportion $(32.5 \%)$ of the non-OCD sample in the current study. There were no differences found in morphing fears between religious and non-religious groups in those reporting OCD. The reason why the OCD group may be different from the nonOCD group in terms of MFQ scores may be explained by the large variation in the OCD group and relatively smaller sample size. Further research will be required to ascertain whether the larger variability of MFQ scores in the OCD group has masked any difference in morphing fears that could be explained by religiousness. 
There are a number of clinical implications of the current research. The finding that morphing fear may be related to OCD and mental contamination is consistent with Rachman's (2006) hypothesis that morphing fear is a form of mental contamination. Patients with mental contamination should be routinely assessed for the presence of morphing fears using this measure. Once identified, it is suggested that patients with morphing fears receive a modified form of cognitive behaviour therapy for mental contamination as described elsewhere (cf. Coughtrey et al., 2013; Rachman, Coughtrey, Shafran \& Radomsky, 2014). Such treatment would involve a range of behavioural experiments to gather evidence relevant to the fear.

The main limitation of this study is that the clinical samples were based on participants' self-report of a current diagnosis rather than a clinical diagnosis per se. Thus, a non-OCD-reporting and analogue self-reporting OCD sample was used for testing of the measure's factor structure, reliability and validity. Furthermore, although the test-retest reliability was found to be very good, especially considering the long mean time interval (18 months), this long time frame was simultaneously a limitation in the current study as test-retest score differences may not be entirely based on instrument unreliability.

Future research should establish a cut-off score to identify clinically relevant morphing-fearful patients. In addition to using a cut-off score, the authors recommend an extreme score (4) on a single item or a high score (3) on two or more items may warrant follow-up since morphing fear symptoms can be highly specific (e.g. reverse morphing may be the primary concern). Future research should test the sensitivity and specificity of the scale to allow confident use of the measure for identification of morphing fears and evaluation of treatment progress and outcome. Testing the discriminant validity between the MFQ and measures of psychosis proneness is 
suggested. Further research recommendations using the MFQ include investigations of clinical correlates of morphing fears and into the adult prevalence of these symptoms. While morphing fears are thought to be relatively rare in adults, these symptoms have recently been found to be endorsed by up to $10.1 \%$ of youth with diagnosed primary OCD (Monzani et al., 2015; Volz \& Heyman, 2007).

In conclusion, the 13-item Morphing Fear Questionnaire is a self-report measure designed to assess whether and to what extent adults experience fears of acquiring characteristics of others and experiencing fundamental changes to or losing parts of their core selves. This measure has shown evidence of reliability and validity, and can be used to screen for morphing fears in patients with OCD. It is hoped the availability of a morphing fear assessment will also help prevent misdiagnosis and promote further research of this phenomenon. The MFQ is quick to administer and score, and is available for clinical and research use free from the authors.

\section{Acknowledgements}

This research was supported by the Charlie Waller Institute. The authors would like to acknowledge S. J. Rachman for his valuable insight into this research.

\section{References}

Abramowitz, J. S., Deacon, B. J, Woods, C. M, Tolin, D. F. (2004). Association between protestant religiosity and obsessive-compulsive symptoms and cognitions. Depression and Anxiety, 20(2), 70-76. doi:10.1002/da.20021

Abramowitz, J. S., Huppert, J. D., Cohen, A. B., Tolin, D. F., \& Cahill, S. P. (2002). Religious Obsessions and Compulsions in a non-clinical sample: The Penn Inventory of Scrupulosity. Behaviour Research and Therapy, 40, 825-838. doi:10.1016/j.janxdis.2006.02.001 
Abramowitz, J. S., Whiteside, S., Lynam, D., \& Kalsy, S. (2003). Is thought-action fusion specific to obsessive-compulsive disorder? A mediating role of negative affect. Behaviour Research and Therapy, 41, 1069-1079. doi:10.1016/S0005-7967(02)002437

American Psychiatric Association. (2000). Diagnostic and statistical manual of mental disorders (4th ed., text rev.). Washington, DC: American Psychiatric Association.

American Psychiatric Association. (2013). Diagnostic and Statistical Manual of Mental Disorders, $5^{\text {th }}$ Edition. Washington, DC: American Psychiatric Association.

Antony, M. A., Orsillo, S. M., \& Roemer, L. (Eds.) (2001). Practitioner's guide to empirically based measures of anxiety. New York: Kluwer Academic/Plenum Publishers.

Bartlett, M. S. (1954). A note on the multiplying factors for various chi square approximations. Journal of Royal Statistical Society, 16(Series B), 296-298.

Beck, A. T., \& Steer, R. A. (1990). Beck Anxiety Inventory manual. San Antonio, TX: The Psychological Corporation.

Beck, A. T., Steer, R. A., \& Brown, G. K. (1996). Manual for the Beck Depression InventoryII. San Antonio, TX: Psychological Corporation.

Berle, D., \& Starcevic, V. (2005). Thought-action fusion: review of the literature and future directions. Clinical Psychology Review, 25(3), 263-284. doi:10.1016/j.cpr.2004.12.001

Berman, N. C., Abramowitz, J. S., Pardue, C. M., \& Wheaton, M. G. (2010). The relationship between religion and thought-action fusion: Use of an in vivo paradigm. Behaviour Research and Therapy, 48(7), 670-674. doi:10.1016/j.brat.2010.03.021

Bolton, D., Dearsley, P., Madronal-Luque, R., \& Baron-Cohen, S. (2002). Magical thinking in childhood and adolescents: development and relation to obsessive compulsion. British Journal of Developmental Psychology, 20, 479-494. doi:10.1348/026151002760390819

Brown, T. A., Di Nardo, P., \& Barlow, D. H. (1994). Anxiety disorders interview schedule adult version (ADIS-IV): Client interview schedule. Oxford: Oxford University Press.

Brown, T. A., Di Nardo, P. A., Lehman, C. L., \& Campbell, L. A. (2001). Reliability of DSMIV anxiety and mood disorders: Implications for the classification of emotional disorders. Journal of Abnormal Psychology, 110, 49-58. doi:10.1037/0021843X.110.1.49

Buja, A., \& Eyuboglu, N. (1992). Remarks on parallel analysis. Multivariate Behavioral Research, 27, 509-540. doi:10.1207/s15327906mbr2704_2

Caldwell-Harris, C. L., Wilson, A. L., LoTempio, E., \& Beit-Hallahmi. B. (2011). Exploring the atheist personality: well-being, awe, and magical thinking in atheists, Buddhists, and Christians. Mental Health, Religion \& Culture, 14(7), 659-672. doi:10.1080/13674676.2010.509847

Calamari, J. E., Weigartz, P. S., Riemann, B. C., Cohen, R. J., Greer, A., Jacobi, D.M., ... Carmin, C. (2004). Obsessive-compulsive disorder subtypes: an attempted replication and extension of a symptom-based taxonomy. Behaviour Research and Therapy, 42, 647-70. doi:10.1016/S0005-7967(03)00173-6

Chapman, L. J., Chapman, J. P, Kwapil, T. R., Eckblad, M. \& Zinser, M. C. (1994). Putatively psychosis-prone subjects 10 years later. Journal of Abnormal Psychology, 103(2), 171183. doi:10.1037/0021-843X.103.2.171 
Chapman, L. J., Chapman, J. P., \& Miller, E. N. (1982). Reliabilities and intercorrelations of eight measures of proneness to psychosis. Journal of Consulting and Clinical Psychology, 50(2), 187-195. doi:10.1037/0022-006X.50.2.187

Chen, F. F. (2007). Sensitivity of goodness of fit indexes to lack of measurement invariance. Structural Equation Modeling, 14, 464-504. doi:10.1080/10705510701301834

Cheung, G. W., \& Rensvold, R. B. (2001). The effects of model parsimony and sampling error on the fit of structural equation models. Organizational Research Methods, 4, 236-264. doi:10.1177/109442810143004

Clark, L. A., \& Watson, D. (1995). Constructing validity: Basic issues in scale development. Psychological Assessment, 7, 309-319. doi:10.1037/1040-3590.7.3.309

Coughtrey A. E., Shafran, S., Lee, M., \& Rachman, S. J. (2013). The Treatment of Mental Contamination: A Case Series. Cognitive and Behavioural Practice, 20(2), 221-231. doi:10.1016/j.cbpra.2012.07.002

Eckblad M., \& Chapman, L. J. (1983). Magical Ideation as an indicator of schizotypy. Journal of Consulting and Clinical Psychology, 51(2), 215-225. doi:10.1037/0022006X.51.2.215

Einstein, D. A., \& Menzies, R. G. (2004a). The presence of magical thinking in obsessive compulsive disorder. Behaviour Research and Therapy, 42, 539-549. doi:10.1016/S0005-7967(03)00160-8

Einstein, D. A. \& Menzies, R. G. (2004b). Role of magical thinking in Obsessive-Compulsive symptoms in an undergraduate sample. Depression and Anxiety, 19, 174-179. doi:10.1002/da.20005

Einstein, D. A., Menzies, R. G. (2006). Magical Thinking in Obsessive-Compulsive Disorder, Panic Disorder and the General Community. Behavioural and Cognitive Psychotherapy, 34(3), 351-357. doi:10.1017/S1352465806002864

Emmelkamp, P. M. G., \& Aardema, F. (1999). Metacognition, specific obsessive-compulsive beliefs and obsessive-compulsive behavior. Clinical Psychology and Psychotherapy, 6, 139-145. doi:10.1002/(SICI)1099-0879(199905)6:2<139::AID-CPP194>3.0.CO;2-9

Foa, E. B., Huppert, J. D., Leiberg, S., Langner, R., Kichic, R., Hajcak, G., \& Salkovskis, P. M. (2002). The Obsessive-Compulsive Inventory: Development and Validation of a short version. Psychological Assessment, 14(4), 485-496. doi:10.1037/10403590.14.4.485

Foa, E. B., \& Kozak, M. J. (1995). DSM-IV Field Trial: Obsessive-Compulsive Disorder. American Journal of Psychiatry, 152, 90-96.

Furr, R. M. (2011). Scale Construction and Psychometrics for Social and Personality Psychology. London, UK: Sage Publications.

Fydrich, T., Dowdall, D., \& Chambless, D. L. (1992). Reliability and validity of the Beck Anxiety Inventory. Journal of Anxiety Disorders, 6(1), 55-61. doi:10.1016/08876185(92)90026-4

Gwilliam, P., Wells, A., \& Cartwright-Hatton, S. (2004). Does meta-cognition or responsibility predict obsessive-compulsive symptoms: a test of the metacognitive model. Clinical Psychology \& Psychotherapy, 11(2), 137-144. doi:10.1002/cpp.402

Hevia, C. (2009). Emotional Contamination: A Lesser Known Subtype of OCD. OCD Newsletter, 23(4), 10-12. 
Kingdon, B., Egan, S. J., \& Rees, C. S. (2012). The Illusory Beliefs Inventory: A new measure of magical thinking in obsessive compulsive disorder. Behavioural and Cognitive Psychotherapy, 40, 39-53. doi:10.1017/S1352465811000245

Kline, P. (1993). The Handbook of Psychological Testing. London, Routledge.

Longman, R. S., Cota, A. A., Holden, R. R. \& Fekken, G. C. (1989). A regression equation for the parallel analysis criterion in principal components analysis: Mean and 95th percentile eigenvalues. Multivariate Behavioral Research, 24, 59-69. doi:10.1207/s15327906mbr2401_4

Lorenzo-Seva, U. \& Ferrando, P. J. (2006). FACTOR: A computer program to fit the exploratory factor analysis model. Behavior Research Methods Instruments \& Computers, 38(1), 88-91. doi:10.3758/BF03192753

Marsh, H.W., Hau, K.T. \& Wen, Z., (2004). In search of golden rules: Comment on hypothesis testing approaches to setting cutoff values for fit indexes and dangers in overgeneralising Hu \& Bentler's (1999) findings. Structural Equation Modelling, 11, 320-341. doi:10.1207/s15328007sem1103_2

Melli, G., Carraresi, C., Stopani, E., Radomsky, A., \& Bulli, F. (2015). Factor structure and temporal stability of the Vancouver Obsessional Compulsive Inventory - Mental Contamination Scale (VOCI-MC) and psychometric properties of its Italian version. Comprehensive Psychiatry, 58, 198-204. doi:10.1016/j.comppsych.2014.12.017

Muthén, B. \& Kaplan D. (1985). A comparison of some methodologies for the factor analysis of non-normal Likert variables. British Journal of Mathematical and Statistical Psychology, 38, 171-189. doi:10.1111/j.2044-8317.1985.tb00832.x

Muthén B. O., du Toit S. H. C., \& Spisic D. (1997). Robust inference using weighted least squares and quadratic estimating equations in latent variable modeling with categorical and continuous outcomes. Unpublished manuscript, University of California, Los Angeles.

Monzani, B., Jassi, A., Heyman, I., Turner, C., Volz, C., \& Krebs, G. (2015). Transformation obsessions in paediatric obsessive-compulsive disorder: Clinical characteristics and treatment response to cognitive behaviour therapy. Journal of Behavior Therapy and Experimental Psychiatry, 48, 75-81. doi:10.1016/j.jbtep.2015.02.004

Olatunji, B. O., Sawchuk, C. N., Lohr, J. M., \& de Jong, P. J. (2004). Disgust domains in the prediction of contamination fear. Behaviour Research and Therapy, 42, 93-104. doi:10.1016/S0005-7967(03)00102-5

Rachman, S. J. (1994). Pollution of the mind. Behaviour Research and Therapy, 32, 311-314. doi:10.1016/0005-7967(94)90127-9

Rachman, S. J. (2004). Fear of Contamination. Behaviour Research and Therapy, 42, $1227-$ 1255. doi:10.1016/j.brat.2003.10.009

Rachman, S. J. (2006). The fear of contamination: Assessment and treatment. Oxford: Oxford University Press.

Rachman, S. J. Coughtrey, A. E., Shafran, R. \& Radomsky, A. S. (2014). Oxford Guide to the Treatment of Mental Contamination. Oxford: Oxford University Press. doi:10.1093/med:psych/9780198727248.001.0001

Rachman, S. J., \& de Silva, P. (1978). Normal and abnormal obsessions. Behaviour Research and Therapy, 16, 233-248. doi:10.1016/0005-7967(78)90022-0 
Rachman, S. J., \& Hodgson, R. J. (1980). Obsessions and compulsions. Englewood Cliffs, NJ: Prentice Hall.

Rachman, S. J., Thordarson, D. S., Shafran, R., \& Woody, S. R. (1995). Perceived Responsibility: Structure and Significance. Behaviour Research and Therapy, 33, 779784. doi:10.1016/0005-7967(95)00016-Q

Radomsky, A. S., Rachman, S. J., Shafran, R., Coughtrey, A. E., \& Barber, K. C. (2014). The nature and assessment of mental contamination: A psychometric analysis. Journal of Obsessive-Compulsive and Related Disorders, 3, 181-187. doi:10.1016/j.jocrd.2013.08.003

Rapee, R. M., Craske, M. G., Brown, T. A., \& Barlow, D. H. (1996). Measurement of perceived control over anxiety-related events. Behavior Therapy, 27, 279-291. doi:10.1016/S0005-7894(96)80018-9

Rasmussen, S. A., \& Eisen, J. L. (1992). The epidemiology and differential diagnosis of obsessive compulsive disorder. Journal of Clinical Psychiatry, 53, 4-10. doi:10.1007/978-3-642-77608-3_1

Rassin, E., Diepstraten, P., Merckelbach, H., \& Muris, P. (2001). Thought-action fusion and thought suppression in obsessive-compulsive disorder. Behaviour Research and Therapy, 39, 757-764. doi:10.1016/S0005-7967(00)00051-6

Rassin, E., \& Koster, E. (2003). The correlation between thought-action fusion and religiosity in a normal sample. Behaviour Research and Therapy, 41, 361-368. doi:10.1016/S0005-7967(02)00096-7

Rassin, E., Merckelbach, H., Muris, P., \& Schmidt, H. (2001). The thought-action fusion scale: Further evidence for its reliability and validity. Behaviour Research and Therapy, 39, 537-544. doi:10.1016/S0005-7967(00)00031-0

Rust, J. \& Golombok, S. (2009). Modern Psychometrics (3rd Edition). London: Taylor and Francis.

Shafran, R., Thordarson, D. S., \& Rachman, S. J. (1996). Thought-action fusion in obsessivecompulsive disorder. Journal of Anxiety Disorders, 10, 379-391. doi:10.1016/08876185(96)00018-7

Sica, C., Norvara, C., \& Sanavio, E. (2002). Religiousness and obsessive-compulsive cognitions and symptoms in an Italian population. Behaviour Research and Therapy, 40, 813-823. doi:10.1016/S0005-7967(01)00120-6

Siev, J. \& Cohen, A. B. (2007). Is thought-action fusion related to religiosity? Differences between Christians and Jews. Behaviour Research and Therapy, 45(4), 829-837. doi:10.1016/j.brat.2006.05.001

Taylor, S. (1998). Assessment of Obsessive Compulsive Disorder. In R. P. Swinson, M. M. Antony, S. Rachman, \& M. A. Ritcher (Eds.), Obsessive-Compulsive Disorder: Theory, Research and Treatment. New York, NY: Guildford Press.

Thordarson, D. S., Radomsky, A. S., Rachman, S. J., Shafran, R., Sawchuk, C. N., \& Hakstian, A. R. (2004). The Vancouver Obsessional Compulsive Inventory (VOCI). Behaviour Research and Therapy, 42, 1289-1314. doi:10.1016/j.brat.2003.08.007

Timmerman, M. E., \& Lorenzo-Seva, U. (2011). Dimensionality Assessment of Ordered Polytomous Items with Parallel Analysis. Psychological Methods, 16, 209-220. doi:10.1037/a0023353 
Velicer, W. F. (1976). Determining the number of components from the matrix of partial correlations. Psychometrika, 41, 321-327. doi:10.1007/BF02293557

Volz, C., \& Heyman, I. (2007). Case series: Transformation obsession in young people with obsessive-compulsive disorder (OCD). Journal of the American Academy of Child \& Adolescent Psychiatry, 46(6), 766-772. doi:10.1097/chi.0b013e3180465a2e

Westen, D., \& Rosenthal, R. (2003). Quantifying construct validity: Two simple measures. Journal of Personality and Social Psychology, 84, 608-618. doi:10.1037/00223514.84.3.608

Zysk, E., (2013). Aetiology, Phenomenology, Assessment and Treatment of Contamination Fears in Obsessive Compulsive Disorder. Unpublished doctoral dissertation, University of Reading, Reading, UK.

Zysk, E., Shafran, R., \& Williams, T. I. (2105). A Single-Case Evaluation of the Treatment of Morphing Fears. Manuscript in preparation. 
Table 1. Item analyses of MFQ in the N-OCD $(n=760)$ and SR-OCD $(n=140)$ samples, and factor loadings based on the one-factor solution from the exploratory factor analysis $(n=379)$

\begin{tabular}{|c|c|c|c|c|c|c|c|c|c|c|c|c|c|c|c|}
\hline \multirow[t]{2}{*}{ Item } & \multicolumn{2}{|c|}{$M$} & \multicolumn{2}{|c|}{$S D$} & \multicolumn{2}{|c|}{ Range } & \multicolumn{2}{|c|}{ SK } & \multicolumn{2}{|c|}{$\mathbf{K U}$} & \multicolumn{2}{|c|}{$\mathbf{M}_{\text {rit }}$} & \multicolumn{2}{|c|}{$\alpha w / 0$} & \multirow[t]{2}{*}{ Loading } \\
\hline & $\begin{array}{l}\mathrm{N}- \\
\mathrm{OCD}\end{array}$ & $\begin{array}{l}\text { SR- } \\
\text { OCD }\end{array}$ & $\begin{array}{l}\mathrm{N}- \\
\mathrm{OCD}\end{array}$ & $\begin{array}{l}\text { SR- } \\
\text { OCD }\end{array}$ & $\begin{array}{l}\mathrm{N}- \\
\mathrm{OCD}\end{array}$ & $\begin{array}{l}\text { SR- } \\
\text { OCD }\end{array}$ & $\begin{array}{l}\mathrm{N}- \\
\mathrm{OCD}\end{array}$ & $\begin{array}{l}\text { SR- } \\
\text { OCD }\end{array}$ & $\mathrm{N}-\mathrm{OCD}$ & $\begin{array}{l}\text { SR- } \\
\text { OCD }\end{array}$ & $\begin{array}{l}\mathrm{N}- \\
\mathrm{OCD}\end{array}$ & $\begin{array}{l}\text { SR- } \\
\text { OCD }\end{array}$ & $\begin{array}{l}\mathrm{N}- \\
\mathrm{OCD}\end{array}$ & $\begin{array}{l}\text { SR- } \\
\text { OCD }\end{array}$ & \\
\hline $\begin{array}{l}\text { Seeing a disfigured person could increase the } \\
\text { chance that I will become like that. }\end{array}$ & .07 & .43 & .31 & .90 & $0-3$ & $0-4$ & 5.51 & 2.36 & 35.03 & 5.26 & .40 & .54 & .81 & .90 & .70 \\
\hline $\begin{array}{l}\text { If I wear an item of clothing of an immoral } \\
\text { individual, I could become immoral myself. }\end{array}$ & .14 & .58 & .46 & 1.02 & $0-4$ & $0-4$ & 4.32 & 1.73 & 22.81 & 2.06 & .41 & .58 & .80 & .89 & .65 \\
\hline $\begin{array}{l}\text { I worry I can magically be transformed into } \\
\text { someone or something else. }\end{array}$ & .08 & .59 & .38 & 1.19 & $0-4$ & $0-4$ & 6.09 & 1.96 & 44.02 & 2.55 & .58 & .69 & .79 & .89 & .75 \\
\hline $\begin{array}{l}\text { I perform repetitive physical or mental acts to } \\
\text { prevent myself from changing into someone or } \\
\text { something I do not wish to be. }\end{array}$ & .21 & 1.24 & .57 & 1.53 & $0-4$ & $0-4$ & 3.27 & .76 & 11.73 & -1.01 & .49 & .68 & .80 & .89 & .63 \\
\hline $\begin{array}{l}\text { I would avoid walking in the airstream of a weird } \\
\text { individual so I do not become like that person. }\end{array}$ & .09 & .51 & .39 & .99 & $0-3$ & $0-4$ & 5.20 & 2.11 & 30.03 & 3.74 & .50 & .45 & .80 & .90 & .66 \\
\hline $\begin{array}{l}\text { When I behave like someone I strongly dislike, I } \\
\text { fear that I might be turning into that particular } \\
\text { person. }\end{array}$ & .56 & .99 & .84 & 1.22 & $0-4$ & $0-4$ & 1.54 & .94 & 2.02 & -.39 & .50 & .61 & .81 & .89 & .76 \\
\hline $\begin{array}{l}\text { Simply thinking about a person I would not wish to } \\
\text { be can change me into that person. }\end{array}$ & .06 & .46 & .34 & .87 & $0-4$ & $0-4$ & 7.76 & 2.02 & 70.50 & 3.81 & .56 & .69 & .80 & .89 & .78 \\
\hline $\begin{array}{l}\text { I can pick up mental illness by direct or indirect } \\
\text { contact with mentally ill people. }\end{array}$ & .06 & .31 & .32 & .74 & $0-4$ & $0-3$ & 6.67 & 2.44 & 56.11 & 5.16 & .52 & .49 & .80 & .90 & .70 \\
\hline $\begin{array}{l}\text { I check to ensure I am not turning into someone or } \\
\text { something else. }\end{array}$ & .21 & .71 & .56 & 1.20 & $0-4$ & $0-4$ & 3.26 & 1.57 & 12.80 & 1.18 & .50 & .69 & .80 & .89 & .68 \\
\hline $\begin{array}{l}\text { I would avoid standing near a homeless person so I } \\
\text { do not have the same fate. }\end{array}$ & .04 & .28 & .26 & .74 & $0-3$ & $0-4$ & 8.53 & 2.96 & 81.52 & 8.64 & .45 & .60 & .80 & .89 & .76 \\
\hline $\begin{array}{l}\text { Saying the name of someone whom I fear or } \\
\text { strongly dislike could make me become like that } \\
\text { person. }\end{array}$ & .02 & .32 & .16 & .70 & $0-3$ & $0-3$ & 12.23 & 2.24 & 77.91 & 4.30 & .47 & .74 & .81 & .89 & .87 \\
\hline $\begin{array}{l}\text { Others can pick up fragments of my character if I } \\
\text { am not careful. }\end{array}$ & .23 & .69 & .62 & 1.19 & $0-4$ & $0-4$ & 3.26 & 1.58 & 12.26 & 1.17 & .53 & .55 & .79 & .90 & .71 \\
\hline $\begin{array}{l}\text { When near someone undesirable, I do magical } \\
\text { things to protect me from becoming like that } \\
\text { person. }\end{array}$ & .02 & .48 & .23 & 1.07 & $0-4$ & $0-4$ & 12.68 & 2.20 & 80.33 & 3.63 & .55 & .75 & .80 & .89 & .99 \\
\hline
\end{tabular}

Note: $\mathrm{MFQ}=$ Morphing Fear Questionnaire; N-OCD = Sample reporting never having had OCD; SR-OCD = Sample reporting current OCD; $M=$ Mean; $S D=$ Standard Deviation; $\mathrm{SK}=$ Skewness; KU = Kurtosis; $\mathrm{M}_{\text {rit }}=$ Mean corrected item-total correlation; $\alpha$ w/o = Cronbach's alpha-if-item-deleted. 
Table 2. Pearson's correlations between the MFQ and the OCI-R, VOCI-MC, BAI, BDI-II, TAF, and MIS for those reporting never having had OCD (N-OCD, $n=760)$ and those reporting having current OCD (SR-OCD, $n=140)$

\begin{tabular}{|c|c|c|}
\hline \multicolumn{3}{|c|}{ Correlations with MFQ } \\
\hline & $\mathrm{N}-\mathrm{OCD}$ & SR-OCD \\
\hline \multicolumn{2}{|c|}{ Convergent measures } & 3 \\
\hline OCI-R & $.48 * *$ & $.49 * *$ \\
\hline VOCI-MC & $.52 * *$ & $.46^{* *}$ \\
\hline TAF & $.46^{* *}$ & $.45 * *$ \\
\hline MIS & $.46^{* *}$ & $.66^{* *}$ \\
\hline \multicolumn{3}{|c|}{ Divergent measures } \\
\hline BAI & $.27 * *$ & $.34 * *$ \\
\hline BDI-II & $.32 * *$ & $.27 * *$ \\
\hline
\end{tabular}

** All one-tailed $p$ values are $<.005$.

Note: $\mathrm{MFQ}=$ Morphing Fear Questionnaire; $\mathrm{N}-\mathrm{OCD}=$ Sample reporting never having had OCD; SR-OCD $=$ Sample reporting current OCD; OCI-R $=$ ObsessiveCompulsive Inventory Revised; VOCI-MC $=$ Vancouver Obsessive Compulsive Inventory - Mental Contamination; BAI = Beck Anxiety Inventory, BDI-II = Beck Depression Inventory; TAF = Thought Action Fusion scale; MIS = Magical Ideation Scale. 


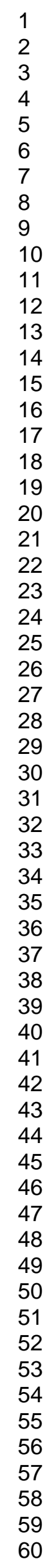

John Wiley \& Sons 